\title{
Early Screening for Autism Spectrum Disorder in Ex-preterm Infants: A Tunisia Prospective Survey
}

\author{
Ben Touhemi Donia ${ }^{1,4 *}$, Khemakehem Khaoula ${ }^{1,4}$, Majdoub Yosra ${ }^{2,4}$, \\ Hadjkacem Imen ${ }^{1,4}$, Boudabous Jaweher ${ }^{1,4}$, Hamida Nedia ${ }^{3,4}$, Ayadi \\ Hela $^{1,4}$ and Moalla Yousr ${ }^{1,4}$ \\ ${ }^{1}$ Department of Child and Adolescent Psychiatry in the University Hospital \\ HediChaker. Sfax, Tunisia \\ ${ }^{2}$ Department of Preventive Medicine in the University Hospital HediChaker. Sfax, \\ Tunisia \\ ${ }^{3}$ Department of Neonatology in the University Hospital HediChaker. Sfax, Tunisia \\ ${ }^{4}$ Faculty of Medicine of Sfax, Tunisia \\ *Corresponding Author: Ben Touhemi Donia, Department of Child and Adolescent \\ Psychiatry in the University Hospital HediChaker. Sfax, Faculty of Medicine of Sfax, \\ Tunisia.
}

\begin{abstract}
Purpose: The aim of the study was to screen autism spectrum disorder (ASD) in preterm children (born before 37 weeks of gestation). The study also aimed to identify maternal and neonatal risk factors associated with a positive screen.

Method: Sixty-four ex-preterm children were recruited for a two-round examination at the age of 18 and 24 months. All children were accompanied by one of their parents. The consultation included a psychiatric interview and mainly the filling of the Modified Checklist for Autism in Toddlers (M- CHAT) scale.

Results: Thirteen (20.3\%) of the 64 Ex-preterm children were screened positive on the M-CHAT at 18 months compared to six $(11.76 \%)$ of the 51 infants who were re-examined at 24 months. The follow-up interview revealed that three of the preterm children were diagnosed with autism based on the DSM 5 criteria. The positive screened preterm children were born after 32 weeks of gestation and displayed higher incidence of pathological fetal heart rate. In addition, chorioamniotitis was significantly associated with positive autism screening. Multivariable analysis showed that only pathological fetal heart rate was independently associated with M-CHAT-positive screen (odds ratio 9.25, $\mathrm{p}=0.02$, 95\% confidence interval 51.3-62.09).

Conclusions: Our study as well as literature studies provide evidence that prematurity increases the risk of ASD. A pathological fetal heart rate and chorioamniotitis were significantly associated with positive autism screening. The nature of the associations between prematurity and this risk remains unclear.
\end{abstract}

Keywords: Autism Spectrum Disorder; Prematurity; Screening; Risk Factors

\section{Abbreviation}

ASD: Autism Spectrum Disorder; BW: Birth Weight; GA: Gestational Age; M-CHAT: Modified-Checklist for Autism in Toddlers.

\section{Introduction}

Autism Spectrum Disorder (ASD) is a group of neurodevelopmental disorders. According to DSM 5 [1], it is characterized by the presence of persistent difficulties in social communication and

Citation: Ben Touhemi Donia., et al. "Early Screening for Autism Spectrum Disorder in Ex-preterm Infants: A Tunisia Prospective Survey". Acta Scientific Paediatrics 5.1 (2022): 14-20. 
interaction, and restricted repetitive behavior, interests, or activities, presently or by history. These symptoms occurred an early developmental age. ASD is considered as an important public health problem to its high prevalence, long-term evolution, and its significant cost to the healthcare system [2].

The prevalence of ASD has increased in recent years. According to estimates from the Centers for Disease Control and Prevention's Autism and Developmental Disabilities Monitoring Network [4], one in 68 children has been identified with ASD, with a prevalence 4.5 times higher in boys ( 1 in 42 ) than girls ( 1 in 189). In Tunisia, it is about 35/10000 according to a screening study carried out on a population of 866 children aged 18 months [5].

The etiology of ASD is currently unknown. It has been suggested that this disorder affects the brain development and interfere with environmental and genetic factors [6]. Among the environmental risk factors, prematurity was identified as playing a role in the pathophysiology and the severity of this disorder [7]. Several studies have suggested that preterm children have higher risk of autism diagnosis than children born at term [7-11].

Nowadays, authors are interested in the screening of autism at an early age. In fact, early diagnosis and early intervention in case of ASD ameliorate considerably the clinical symptoms, the prognosis and the evolution [12]. In particular, the screening could be interesting in high-risk population such as preterm children. Therefore, the objective of the present study was to screen ASD in early preterm children at the age of 18 and 24 months. The study also aimed to identify maternal and neonatal risk factors associated with a positive screen.

\section{Methods}

Type of study

The present study was prospective, descriptive and analytical. It was carried out over a 12-month period (Mai 2016-May 2017). It was performed in the Neonatal Department (Hedi Chaker University Hospital, Sfax, Tunisia).

\section{Study population}

Inclusion criteria

A cohort of 64 ex-preterm infants, at the age of 18 months old, regularly followed up in the out care of neonatal Department (Hedi Chaker Hospital, Sfax, Tunisia) was enrolled.
According to world health organization, preterm is defined as babies born alive before 37 weeks of pregnancy are completed. There are sub-categories of preterm birth, based on gestational age:

- $\quad$ Extremely preterm (less than 28+0 weeks)

- $\quad$ Very preterm $(28+0$ to $31+6$ weeks $)$

- Moderate to late preterm $(32+0$ to $36+6$ weeks).

\section{Exclusion criteria}

Infants with hearing impairment, blindness, or severe cerebral palsy were excluded due to the anticipated high rate of false positive screen due to their underlying conditions.

\section{Ethical statement}

For all participants, an informed consent by the person legally responsible for the children was obtained. The study was approved by the Ethic Committee: Committee of people protection SUD « C.P.P.SUD », reference: CCP SUD N 0290/2021.

\section{Study procedure}

A medical chart was performed to characterize our cohort and to collect demographic, prenatal, intrapartum, acute postnatal and short time outcome data for all infants.

- Demographic data included gestational age (GA) at birth, birth weight (BW), and gender.

- Maternal data included maternal age, single versus multiple gestation, gestational diabetes, preeclampsia, intra- or antepartum hemorrhage, previous preterm labor during the pregnancy, prenatal infection, and use of antenatal steroids.

- Prenatal and neonatal factors included fetal heart rate abnormalities, vaginal versus cesarean birth, Apgar score at 5 minutes, and need for respiratory and cardiovascular resuscitation.

- $\quad$ The early postnatal data were collected from medical files and included respiratory and metabolic complication, neonatal infection, the need for cardiopulmonary support, duration of mechanical ventilation and supplemental oxygen requirement.

All children were accompanied by one of their parents. The child psychiatrist examined the child and completed the Modified Checklist for Autism in Toddlers (M- CHAT) at two times: 18 and 24 
months. The diagnosis of the ASD according to the DSM 5 criteria has been retained at the age of 24 months.

\section{ASD screening tool}

The Modified-Checklist for Autism in Toddlers (M-CHAT), is a 23 items (yes/no) parent-report checklist developed to screen children aged 16 to 30 months for early signs of autism disorder [13]. The M-CHAT evaluates sensory responsiveness (eg, responds to sound or touch), social interaction (eg, the child imitates the parents), early language and communication (eg, responds when his name is called), and joint attention (eg, the child follows a pointy to an object across the room). Psychometric data from this questionnaire prove high sensitivity and specificity (87\% and 99\%, respectively).Among the23-items (yes/no), six are considered as predictive of autism ('critical' items 2, 7, 9, 13, 14, 15) and seventeen non-critical items. When two or more 'critical' items orany three itemsare failing, the child is screened positive for ASD.

The ASD was screened by passing the parents the Tunisian validated version of the M-CHAT [5] and subsequently by a clinical interview. This questionnaire showed an average overall internal consistency with a Cronbach alpha of 0.53 .

\section{Statistical analysis}

Statistical analysis of all factors was performed using Statistical Package for the Social Sciences (SPSS) in its 20th release. Qualitative variables were expressed as percentages. For quantitative variables, the normality of the distribution waschecked by the Kolmogorov-Smirnov test and the Shapiro-Wilk test. An estimate of the means with their standard deviations and of the median with min and max was thus carried out.

The associations between the variables were studied using hypothesis tests. The comparison between two qualitative variables was carried out by the Pearson "chi2" test when the conditions were verified otherwise the exact Fisher test was used. The Student test was used for the comparison of two means when the distribution is Gaussian and by the non-parametric U test of Mann-Whitney when the distribution is not Gaussian. The level of statistical significance was set at $\mathrm{p}<0.05$ (alpha level of 5\%).

The factors associated with a positive screen of ASD were studied by calculating unadjusted (in univariate analysis) and adjusted Odds Ratio (aOR) after multivariate analysis using binary logistic regression. We retained a risk of error of $25 \%$ to include the indicator variables in the multivariate analysis.

\section{Results}

Clinical characteristics of preterm cohorts

- The clinical characteristics of pregnancy and delivery are summarized in table 1.

- $\quad$ Pregnancy was multiple in $35.9 \%$ of the cases. The prevalence of pregnancy complications was $62.9 \%$.

- The gestational age at birth ranged from 27 to 36 weeks (average of 30 weeks \pm 2.4 ), and the birth weight ranged from 800 to $3050 \mathrm{~g}$ (average of $1444 \mathrm{~g} \pm 400$ ). All children were hospitalized in the Neonatology Department. Complications during hospitalization were observed in $75 \%$ of the subjects.

- A fetal ultrasound was performed for all children. The investigation showed abnormalities in $37.5 \%$ of cases.

- $\quad$ Table 2 shows the postnatal characteristics of our cohort.

\begin{tabular}{|c|c|}
\hline Clinical Characteristic & Value n (\%) \\
\hline \multicolumn{2}{|l|}{ Pregnancy } \\
\hline Maternal age $>35 \mathrm{y}$ & $24(37.5 \%)$ \\
\hline Multiple pregnancy & $23(35.90 \%)$ \\
\hline Preeclampsia & $17(26.56 \%)$ \\
\hline Gestational diabetes & $1(1.56 \%)$ \\
\hline Intrauterine growth retardation & $13(20.31 \%)$ \\
\hline $\begin{array}{l}\text { Premature rupture of } \\
\text { membranes, }\end{array}$ & $15(23.43 \%)$ \\
\hline Chorioamnionitis & $2(3.12 \%)$ \\
\hline \multicolumn{2}{|c|}{ Labor and delivery } \\
\hline $\begin{array}{l}\text { Gestational age median (range) } \\
<28 \mathrm{Wk} \\
28-32 \mathrm{Wk} \\
>32 \mathrm{Wk}\end{array}$ & $\begin{array}{c}30 \text { weeks } \pm 2.4 \\
11(17.20 \%) \\
35(54.70 \%) \\
18(28.10 \%) \\
\end{array}$ \\
\hline Birth weight, median & $1440 \mathrm{~g} \pm 391 \mathrm{~g}$ \\
\hline Male gender & $26(40.68 \%)$ \\
\hline Abnormal fetal heart rate & $19(29.70 \%)$ \\
\hline Cesarean delivery & $54(84.4 \%)$ \\
\hline Apgar score at $5 \mathrm{~min}<7$ & $4(6.3 \%)$ \\
\hline $\begin{array}{l}\text { Respiratory resuscitation in } \\
\text { delivery room, }\end{array}$ & $33(51.6 \%)$ \\
\hline $\begin{array}{l}\text { Circulatory resuscitation in } \\
\text { delivery room }\end{array}$ & $5(7.80 \%)$ \\
\hline
\end{tabular}

Table 1: Clinical characteristics of pregnancy and delivery in the preterm cohort $(n=64)$. 


\begin{tabular}{|l|c|}
\hline Postnatal characteristics & Value \\
\hline Mechanical ventilation & $20(31.30 \%)$ \\
\hline Postnatal complication & $48(75 \%)$ \\
\hline Neonatal infection & $34(53.10 \%)$ \\
\hline Hypoglycemia & $17(26.56 \%)$ \\
\hline Respiratory distress & $33(51.60 \%)$ \\
\hline Neonatal jaundice & $22(34.40 \%)$ \\
\hline Cerebral hemorrhage & $8(12.5 \%)$ \\
\hline
\end{tabular}

\begin{tabular}{|c|c|c|c|}
\hline $\begin{array}{l}\text { Type of Pregnancy } \\
\text { Single } \\
\text { Multiple }\end{array}$ & $\begin{array}{l}31(68.88 \%) \\
14(31.22 \%)\end{array}$ & $\begin{array}{l}5(83.30 \%) \\
1(16.70 \%)\end{array}$ & $0.65^{*}$ \\
\hline $\begin{array}{l}\text { Preeclampsia } \\
\text { Yes } \\
\text { No }\end{array}$ & $\begin{array}{l}16(35.60 \%) \\
29(64.40 \%)\end{array}$ & $\begin{array}{c}1(6.70 \%) \\
5(83.30 \%)\end{array}$ & $0.33^{*}$ \\
\hline $\begin{array}{l}\text { Gestationaldiabetes } \\
\text { Yes } \\
\text { No }\end{array}$ & $\begin{array}{c}1(2.20 \%) \\
44(97.80 \%)\end{array}$ & $\begin{array}{c}0 \\
6(100 \%)\end{array}$ & $1^{*}$ \\
\hline $\begin{array}{l}\text { Intrauterinegrowth } \\
\text { retardation } \\
\text { Yes } \\
\text { No } \\
\end{array}$ & $\begin{array}{l}6(13.30 \%) \\
39(36.70)\end{array}$ & $\begin{array}{l}3(50 \%) \\
3(50 \%)\end{array}$ & $0.06^{*}$ \\
\hline $\begin{array}{l}\text { Chorioamnionitis } \\
\text { Yes } \\
\text { No }\end{array}$ & $\begin{array}{c}0 \\
45(100 \%)\end{array}$ & $\begin{array}{l}2(33.30 \%) \\
4(66.70 \%)\end{array}$ & $0.01 *$ \\
\hline $\begin{array}{l}\text { Fetalheart rate } \\
\text { Normal } \\
\text { Pathological }\end{array}$ & $\begin{array}{c}37(90.20 \%) \\
4(9.80 \%)\end{array}$ & $\begin{array}{l}3(50 \%) \\
3(50 \%)\end{array}$ & $0.03^{*}$ \\
\hline $\begin{array}{l}\text { Gender } \\
\text { Male } \\
\text { Female }\end{array}$ & $\begin{array}{l}19(42.20 \%) \\
26(57.80 \%)\end{array}$ & $\begin{array}{l}3(50 \%) \\
3(50 \%)\end{array}$ & $1^{*}$ \\
\hline $\begin{array}{l}\text { Gestationalage } \\
\leq 32 \text { SA } \\
>32 \text { SA }\end{array}$ & $\begin{array}{c}36(80 \%) \\
9(20 \%)\end{array}$ & $\begin{array}{l}1(16.70 \%) \\
5(83.30 \%)\end{array}$ & $0.045^{*}$ \\
\hline $\begin{array}{l}\text { Birthweight } \\
<1500 \mathrm{~g} \\
>1500\end{array}$ & $\begin{array}{l}27(60 \%) \\
18(40 \%)\end{array}$ & $\begin{array}{l}3(50 \%) \\
3(50 \%)\end{array}$ & 0.48 \\
\hline $\begin{array}{l}\text { Apgar at } 5 \mathrm{~min} \\
<6 \\
>6\end{array}$ & $\begin{array}{l}12(26.66 \%) \\
33(73.33 \%)\end{array}$ & $\begin{array}{l}1(16.70 \%) \\
5(83.30 \%)\end{array}$ & 0.54 \\
\hline
\end{tabular}

Table 3: Distribution of clinical risk factors with normal/ abnormal M-CHAT score at the age of 24 months $(n=51)$.

* Fishertest. variate analysis showed that only pathological fetal heart rate was independently associated with M-CHAT-positive screen (aOR 9.25, $\mathrm{p}=0.02,95 \%$, confidence interval 51.3-62.09). Regarding the postnatal studied factors there was no association with positive screen for ASD (Table 4).

\begin{tabular}{|l|c|c|c|}
\hline Variable & $\begin{array}{c}\text { Normal } \\
(\mathbf{n = 4 5 )}\end{array}$ & $\begin{array}{c}\text { Abnormal } \\
(\mathbf{n = 6 )}\end{array}$ & $\mathbf{p}$ \\
\hline Maternel age & & & \\
Mean & $31 \pm 5$ & $32 \pm 5$ & 0.5 \\
$>35$ years & $18(40 \%)$ & $2(33.30 \%)$ & $1^{*}$ \\
$<35$ years & $27(60 \%)$ & $4(66.70 \%)$ & \\
\hline
\end{tabular}

\begin{tabular}{|l|c|c|c|}
\hline Variable & $\begin{array}{c}\text { Normal } \\
(\mathbf{n = 4 5 )}\end{array}$ & $\begin{array}{c}\text { Abnormal } \\
(\mathbf{n = 6 )}\end{array}$ & $\mathbf{p}$ \\
\hline Hospitalstay (average) & $30.75( \pm 16)$ & $20.66( \pm 9)$ & 0.061 \\
\hline $\begin{array}{l}\text { Mechanical ventilation } \\
\text { Yes } \\
\text { No }\end{array}$ & $17(37.80 \%)$ & $1(16.70 \%)$ & $0.4^{*}$ \\
\hline $\begin{array}{l}\text { Neonatal infection } \\
\text { Yes } \\
\text { No }\end{array}$ & $28(62.20 \%)$ & $5(83.30 \%)$ & \\
\hline $\begin{array}{l}\text { Neonataljaundice } \\
\text { Yes } \\
\text { No }\end{array}$ & $17(37.80 \%)$ & $4(66.70 \%)$ & $0.21^{*}$ \\
\hline
\end{tabular}




\begin{tabular}{|l|c|c|c|}
\hline Respiratory distress & $22(48.90 \%)$ & $3(50 \%)$ & $1^{*}$ \\
Nes & $23(51.10 \%)$ & $3(50 \%)$ & \\
\hline Neonatale & & & \\
Hypoglycaemia & $14(31.10 \%)$ & $3(50 \%)$ & $0.31^{*}$ \\
Yes & $31(68.90 \%)$ & $3(50 \%)$ & \\
No & & & \\
\hline Cerebral haemorrahge & $8(31.10 \%)$ & $2(33.30 \%)$ & 0.58 \\
Yes & $37(82.20 \%)$ & $4(66.70 \%)$ & \\
No & & \\
\hline
\end{tabular}

Table 4: The association between antenatal and natal factors and screening for ASD according to M-CHAT at the age of 24 months.

* Fishertest.

\section{Discussion}

Previous studies have reported a higher risk to develop neurodevelopmental disorder such ASD in preterm infants than the infant born at term. The present study aimed to screen ASD in early preterm infants at the age of 18 and 24 months and to identify maternal and neonatal risk factors associated with a positive screen.

The age of screening picked in our study was 18 months and 24 months. In fact the American Academy of Pediatrics has published guidelines (PAA 2006) [14] supporting the screening for ASD in infants aged 18 months. Generally, many parents express worries as early as 15 and 18 months of age [15]. The M-CHAT can be accurately administered at age 18 months. Nevertheless, at this age, children with ASD may not meet all of the criteria to allow a diagnosis of ASD and can have a negative screen in the M-CHAT. Consequently, we have reexamined these infants at the age of 24 months to gather more information about the stability of the diagnosis and to detect regressive forms of autism. Previous studies have shown that diagnosis of ASD at 2 years of age is possible and stable over time [15].

\section{Prevalence of screening for ASD in preterm infants}

In the current study, the prevalence of screening for ASD among preterm infant by utilizing M-CHAT scale was $20.30 \%$ at 18 months and $11.76 \%$ at 24 months. These findings support a high prevalence of positive initial screenings for ASD in preterm children. In literature, the results of a positive screening test vary from $7 \%$ to $42 \%[12,16-18]$. This variation in rate can be explain by diverse screening tests used, and the difference in inclusion and exclusion criteria.
Concerning the diagnosis of ASD, only three children of those who had positive M-CHAT screen filled the DSM 5 criteria for ASD. Accordingly, the prevalence of ASD in our population was $4.68 \%$ based on a clinical examination following the DSM 5 criteria. Previous studies estimated that ASD prevalence among prematurely born children is about 5 to $8 \%[7,19]$. Whereas, it varies between 1 and $2 \%$ in the general population [1,20]. Recently, a systematic meta-analysis that comprised 3366 preterm infants from 18 studies revealed that the prevalence rate of ASD was $7 \%$ when diagnostic tools were used [9].

A prospective study in Southern Taiwan, included 283 very preterm infants at the age of 5 years. The diagnostic assessments with ADOS and ADI-R has shown ASD incidence rate of 7.7\% [10]. After excluding the preterm children with major neurological disorder, the ASD incidence rate was still high (7.3\%) [10]. Dudova., et al. [18] identified $13 \%$ of the infants with ASD in their study which involved 101 preterm infants at the age of 2 years. They used the screening battery including the Modified Checklist for Autism in Toddlers (M-CHAT), Communication and Symbolic Behavior Scales Developmental Profile Infant-Toddler Checklist (CSBS-DP-ITC), and the Infant/Toddler Sensory Profile (ITSP). Such elevated prevalence of ASD points out the importance to use clinical judgement when suspecting a child as having ASD and not to rely on screening tests only.

\section{Maternal and obstetric factors}

In the present study, chorioamniotitis was associated with a positive screening of M-CHAT. This can be explained by the fact that placental dysfunction and intra-uterine infection are considered as major causes of prematurity and fetal anoxia, which may contribute to development of autism [18].

In the present study, the choice of 35 years as the cut-off age was based on the recommendations of many authors [21,22]. The mean maternal age at conception was higher in children with ASD without significant difference (32 versus 31 years old, $\mathrm{p}=0.5$ ). Prior studies have shown that advanced maternal age increased the risk for ASD [21,22]. A recent review showed that maternal age was associated with an increased risk of ASD when the comparison is limited on age groups of 35 years or older versus 25-29 years [23]. This can be explained by the fact that advanced age at conception was associated with increased risk of pregnancy and obstetric complications, amplified the chance of exposure to medications or pollutions and more genetic mutation [24]. 
Moreover, obstetrical factors (preeclampsia, gestational diabetes, intrauterine growth restriction) that may influence the positive screening rate, were investigated in this study. Nevertheless, they did not display any statistically significance on the screening of ASD. The small size of our sample may reflect the underestimated effect of these pathologies on autism. Many studies underlined the association of maternal and obstetric factors in preterm infant with ASD. Maternal infection, intrauterine growth restriction, placental insufficiency, maternal overweight, gestational diabetes, preeclampsia and pre-pregnancy maternal antidepressant use have been associated with increased risk for autism [22,23,25].

\section{Birth risk factors}

In the present study, different birth factors (GA, BW, Apgar scale, respiratory distress...) seem to increase the risk for ASD. Actually, a significant association was found between the existence of abnormalities in the fetal heart rhythm, which indicates the presence of fetal distress, and the positive screening of ASD. However, we did not find a correlation between a low Apgar score and a positive screening which is controversial with other studies [25]. In addition, several researchers have hypothesized that a set of perinatal conditions that indicate a prolonged or acute deprivation of oxygen for the fetus might be a major risk factor for neuropsychological disorders and could increase the risk of ASD [21,26].

Concerning the association between GA and autism, we found that infants who were born after 32 weeks of gestation, had an increased risk of a positive M-CHAT screen. Our results were in line with those reported by Moore., et al. [12] who found that infants born before 34 weeks of gestation and post-term infants (39-41 GA) had an increased risk of autism, while very preterm infants $(<32 \mathrm{GA})$ were protected against autism.

On the other hand, some authors had demonstrated that a lower GA is considered as significant risk factor to develop ASD [8,12]. The prevalence of positive screening decreases significantly with the increase of GA at birth [27]. However, a recent meta-regression analysis has revealed no significant association between gestational age and the prevalence of ASD [9].

In addition to GA, low BW was considered as a risk factor for autism. In the present study, we didn't found such association. Moore., et al. [12] and Stephens., et al. [17] found that preterm infants with lower BW had a higher risk of positive M-CHAT screens. The controversies in relationship between ASD and low BW could be explained by various maternal or neonatal factors, such as maternal age and health conditions, nutrition deficits, hypoxia, and other obstetrical complications [28].

In addition, different postnatal risk factors for ASD in preterm children were studied. In our sample, no neonatal or postnatal factor were identified to be significantly associated with a positive screen on the M-CHAT, because of our low incidence.

In the review of Guinchat [22], no factor in the neonatal and perinatal periods has been constantly certified as a risk factor for autism. However, some factors have been associated with autism in several studies and should be considered as potential risk factors for ASD, such as late onset bacteraemia, administration of steroids in postnatal period, broncho-pulmonary dysplasia, abnormal MRI studies and cranial ultrasound abnormality $[8,12]$.

The limitation of our study is the small sample of preterm children that were recruited and the absence of a control term children, therefore the identification of risk factors associated with a positive screen in MCHAT could be underestimated.

\section{Conclusion}

Our study as well as literature studies suggest that prematurity increases the risk of ASD. Although, our findings support that late prematurity, a pathological fetal heart rate and chorioamniotitis were significantly associated with positive autism screening. The nature of the associations between prematurity and this risk remains unclear. Future studies are needed to more investigate perinatal and neonatal conditions in preterm infants to better characterize this association.

\section{Acknowledgment}

None.

\section{Bibliography}

1. "American Psychiatric Association". Autism Spectrum Disorder DSM5 (2013).

2. Fuentes J., et al. "Troubles du spectre autistique". International Association for Child and Adolescent Psychiatry Allied Products Chapitre 2 (2012).

3. Harrington JW., et al. "The Clinician's Guide to Autism". Pediatrics in Review 35.2 (2014): 62-78.

4. Christensen DL., et al. "Prevalence and characteristics of autism spectrum disorder among children aged 8 years- $\mathrm{Au}-$ tism and Developmental Disabilities Monitoring Network". (MMWR) Surveillance Summaries 65.3 (2016): 1-23. 
5. N Gaddour., et al. "Autism screening during the second year of life in Tunisia". Neuropsychiatrie l'enfance l'adolescence 60 (2012).

6. Angelidou A., et al. "Perinatal stress, brain inflammation and risk of autism-review and proposal". BMC Pediatrics 12.1 (2012): 89.

7. Johnson S., et al. "Autism Spectrum Disorders in Extremely Preterm Children". The Journal of Pediatrics 156.4 (2010): 525-531.

8. Limperopoulos C., et al. "Positive screening for autism in expreterm infants: prevalence and risk factors". Pediatrics 121.4 (2008): 758-765.

9. S Agrawal., et al. "Prevalence of Autism Spectrum Disorder in Preterm Infants: A Meta-analysis”. Pediatrics 142.3 (2018).

10. Chen L., et al. "Behavioral characteristics of autism spectrum disorder in very preterm birth children". Molecular Autism (2019): 1-9.

11. Burns MMCO., et al. "Premature Birth, Low Birth Weight, and Positive Screening for Autism Spectrum Disorder in an Early Intervention Sample". Journal of Developmental and Physical Disabilities 30. (2018): 689-705.

12. Moore T., et al. "Screening for autism in extremely preterm infants : problems in interpretation". Developmental Medicine and Child Neurology 54. (2012): 514-520.

13. Kleinman JM., et al. "The Modified Cheklist for Autism in Toddlers: A Follow-up Study Investigating the Early Detection of Autism Spectrum Disorders". Journal of Autism and Developmental Disorders 38.5 (2008): 827-839.

14. Council on Children with Disabilities, Section on Developmental Behavioral Pediatrics, Bright Futures Steering Committee et al. Identifying infants and young children with developmental disorders in the medical home: an algorithm for developmental surveillance and screening. Pediatrics 118.1 (2006): 405-420.

15. Yates K and Couteur A Le. "Diagnosing autism / autism spectrum disorders". Paediatrics and Child Health (Oxford). (2016): $1-6$.

16. Robert M. et al. "Extremely low gestational age and very low birth weight for gestational age are risk factors for ASD in a large cohort study of 10-year-old children born at 23-27 weeks gestation". American Journal of Obstetrics and Gynecology (2016).

17. Stephens BE et al. "Screening for Autism Spectrum Disorders in Extremely Preterm". Journal of Developmental and Behavioral Pediatrics 33.7 (2012): 535-541.
18. Dudova I., et al. "Screening for autism in preterm children with extremely low and very low birth weight". Neuropsychiatric Disease and Treatment 10 (2014): 277-282.

19. Pinto-Martin JA., et al. "Prevalence of Autism Spectrum Disorder in Adolescents Born Weighing < 2000 Grams". Pediatrics 128.5 (2011): 883-891.

20. Kim SH., et al. "Predictive Validity of the Modified Checklist for Autism in Toddlers (M-CHAT) Born Very Preterm". The Journal of Pediatrics (2016).

21. Hadjkacem I., et al. "Prenatal, perinatal and postnatal factors associated with autism spectrum disorder". Jornal de Pediatria (2016): 1-7.

22. Guinchat V., et al. "Pre-, peri- and neonatal risk factors for autism". Acta Obstetricia et Gynecologica Scandinavica 91.3 (2012): 287-300.

23. Kim JY., et al. "Environmental risk factors and biomarkers for autism spectrum disorder : an umbrella review of the evidence". The Lancet Psychiatry 6.7 (2019): 590-600.

24. Wu S., et al. "Advanced parental age and autism risk in children: a systematic review and meta-analysis". Acta Psychiatrica Scandinavica 135 (2017): 29-41.

25. Gardener H., et al. "Perinatal and Neonatal Risk Factors for Autism : A Comprehensive Meta-analysis". American Academy of Pediatrics (2011): 344-355.

26. Mahadevan SRCVSKS. "Maternal and birth risk factors for children screening positive for autism spectrum disorders on MCHAT-R". Asian Journal of Psychiatry (2016).

27. Leavey A., et al. "Gestational Age at Birth and Risk of Autism Spectrum Disorders in Alberta, Canada”. The Journal of Pediatrics 162.2 (2013): 361-368.

28. Abou EL-Ela Ramadan., et al. "Study of some perinatal and neonatal risk factors for autism". International Journal of Advanced Research 4.11 (2016): 154-166.

\section{Assets from publication with us}

- Prompt Acknowledgement after receiving the article

- Thorough Double blinded peer review

- Rapid Publication

- Issue of Publication Certificate

- High visibility of your Published work

Website: www.actascientific.com/

Submit Article: www.actascientific.com/submission.php Email us: editor@actascientific.com

Contact us: +919182824667 